\title{
Hybrid advanced oxidation process (HAOP) as an effective pharmaceutical wastewater treatment
}

\author{
Aris Mukimin ${ }^{1, *}$ and Hanny Vistanty ${ }^{1}$ \\ ${ }^{1}$ Center of Industrial Pollution Prevention Technology, Semarang - Indonesia
}

\begin{abstract}
Pharmaceutical wastewater may contain bio-refractory and toxic compounds that cannot be treated by microbiology methods. In addition to low efficiency, bacteria will be collapsed and biomass wash-out will occur and be detected as TSS. Hybrid advanced oxidation process (HAOP), based on the electrochemical method, is highly potential for degradation of stable compounds. Cylinder cathode made of carbon cloth was paired with Ti/PtIr anode and inter-electrode distance of 1-3 cm. The cell was equipped with a magnetic stirrer to improve the oxidation-reduction on the surface of the electrode thus enhancing contact between pollutant and generated oxidator. Applied at electrolyte of $4000 \mathrm{mg} / \mathrm{L}$, ferrous sulfate of $0.2 \mathrm{mM}$, and $\mathrm{pH}$ value of 2.5 , HAOP showed an excellent performance and reached $60 \%, 90 \%$, and $94 \%$ of COD reduction after 3,6 , and 9 hrs.
\end{abstract}

Keywords: HAOP electrocatalytic; pharmacy wastewater; Ti/PtIr anode; carbon cloth cathode;

\section{Introduction}

Pharmaceutical wastewater contains complex compounds and high loading depends on the raw chemicals and production process applied such as fermentation, extraction, and purification [1]. Specific pollutants, e.g., cephalosporin, penicillin, and other compounds categorized as antibiotic may also be found in the wastewater [2]. These compounds are a hardly degradable and persistent soluble matter that may eliminate bacteria and cause washout [3]. Pollutants are then accumulated in the aquatic environment and may inflict hazard pose to the ecosystem. The accumulation will continue to occur due to progressive production and massive consumption on health system (domestic and hospital use, livestock and agricultural purpose [4]. The risk will be higher due to incomplete metabolic excretion of drugs resulting in a negative impact; that is the emergence of resistant pathogens $[5,6]$.

Physical, chemical, and biological treatments are commonly employed for wastewater treatment, including pharmaceutical [7]. Guo et al, 2013 [4] mentioned that adsorption, coagulation, flocculation, and oxidation are ineffective for pharmaceutical wastewater treatment and cannot fulfill the limit of regional regulatory for wastewater disposal. Biological treatment has a strong potential for pharmaceutical wastewater application, however major modifications on the active microorganisms as well as the main technology are needed. DWA (deep well aerobic) and SBR (sequencing batch reactor) has been applied by Hu et al, 2010 [8] and reached a high efficiency of $85 \%$. SBR treatment needs longer retention time (HRT) and higher treatment areas, in addition to the high volume of active sludge. While DWA method has several drawbacks, such as continuous oxygen supply requirement, high production of sludge and risk of antibiotic contamination on the soil. Those methods will also generate residual sludge that will be an inhibitor to aerobic microorganisms. Coskun et al, 2012 [9] applied UASB (up flow anaerobic sludge bed) and UBF (up flow blanked filter) for pharmaceutical wastewater treatment. UASB showed a higher COD reduction of $80-95 \%$ [10]. Moreover, it also produces less sludge with a lower demand for energy. However, it needs a longer start-up and retention time of $13 \mathrm{~d}$, highly sensitive to low temperature and toxic compounds and unable to meet the quality of tap water.

Over the last decade, many studies have focused on pharmaceutical wastewater treatment by advanced oxidation process (AOP) and showed high efficiencies [11]. It can be categorized into two major types, nonphotochemical AOP (cavitation, ozonation, Fenton, ozone/hydrogen peroxide) and photochemical AOP (homogeneous and heterogeneous processes) [12]. The main mechanism of AOP involves oxidation generation and oxidation reaction of oxidator and pollutants [13]. It was able to reduce COD by up to $90 \%$ at initial COD of $500 \mathrm{mg} / \mathrm{L}$. However, the shortcoming of AOP is the requirement of multiple chemicals $\left(\mathrm{O}_{3}, \mathrm{H}_{2} \mathrm{O}_{2}, \mathrm{Fe}^{3+}\right)$ and high cost of investment. The innovation of configuration is highly limited to the exposure of UV-light on $\mathrm{TiO}_{2}$ surface [14]. The activity of catalyst can be easily reduced due to the deposition of solids on the surface of electrode.

\footnotetext{
* Corresponding author: arismukimin@,gmail.com
} 
This study presents the investigation of pharmaceutical wastewater treatment by advanced oxidation process. The main innovation of this research lies on the material of electrode (anode and cathode) and chemicals in addition to degrading pollutants in a much shorter time. The superiority of this technology is its ability to generate multiple mechanisms of degradation and the chemicals used, which is easy to find and inexpensive.

\section{Methods}

\subsection{Materials}

Pharmaceutical wastewater was collected from PT Phapros Indonesia, Semarang. HAOP reactor was constructed using Ti/PtIr plate anode of $2 \mathrm{~cm}$ width and $5 \mathrm{~cm}$ length (Baoji Changli Special Metal Co., LTD, China) and carbon cloth cylinder cathode of $3 \mathrm{~cm}$ inner diameter and $5 \mathrm{~cm}$ length (Fuel Cell Store, USA). The cell configuration is depicted in Fig. 1. Sulphuric acid and ferrous sulfate were of analytical grade and were used without any treatment. Salt as a source of the electrolyte was purchased from a local commercial product. Other reagents used in COD analysis were of analytical grade as required by standard testing method (APHA AWWA).

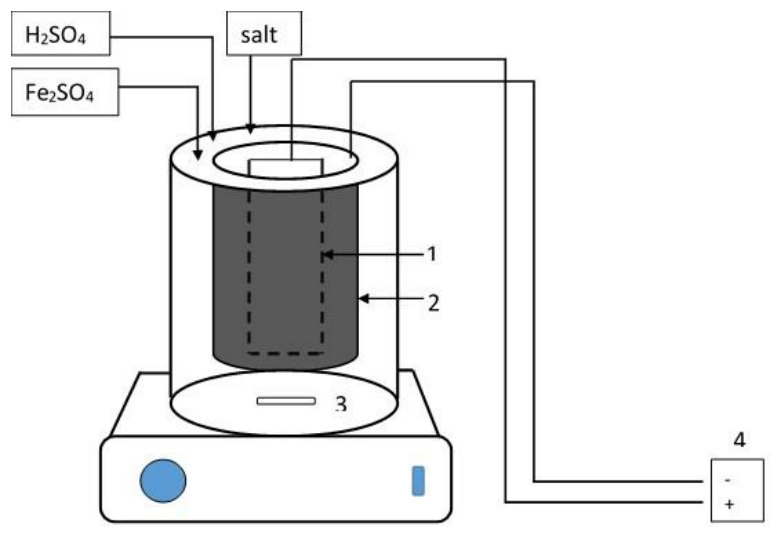

Fig. 1. The configuration of HAOP reactor, consisting of Ti/PtIr anode (1), carbon cloth cathode (2), magnetic stirrer (3), and DC power supply (4)

\subsection{Procedure}

$200 \mathrm{~mL}$ of pharmaceutical wastewater was fed into HAOP cell. $4000 \mathrm{mg} / \mathrm{L}$ salt, $0.2 \mathrm{mM}$ ferrous sulfate and sulphuric acid (as $\mathrm{pH}$ adjustment to 3 ) were then added into the cells. The potential of $6 \mathrm{~V}$ was applied to electrode and a stirring system was employed at 3, 6, and $9 \mathrm{~h}$. Samples were collected for COD (Chemical Oxygen Demand) analysis and current response was observed. The experiment was also performed with salt, sulphuric acid and ferrous sulfate addition as operation variables.

\section{Result and discussion}

\subsection{Effect of materials to the performance of cell}

HAOP cell was able to degrade pharmaceutical wastewater at an initial COD of $1198 \mathrm{mg} / \mathrm{L}$. The process was influenced by several parameters as shown in Fig. 2. The addition of electrolyte directly contributed to COD removal and strictly correlated to the mechanism of degradation process.

The complete addition of chemicals (salt, $\mathrm{H}_{2} \mathrm{SO}_{4}$, and $\mathrm{Fe}_{2} \mathrm{SO}_{4}$ ) showed the highest $\mathrm{COD}$ reduction. It is possible due to the occurrence of three mechanisms, electrocatalytic advanced oxidation process (EAOP), electrocatalytic Fenton reagent process (EFRP) and electrocatalytic flotation process (EFP). Anode material plays an important role in the mechanism of EAOP oxidation. Ti/PtIr electrode installed and connected to the positive polar of DC power supply will degrade pollutants via direct and indirect oxidation. Theoretically, direct oxidation occurs at low potential (below the potential of oxygen evolution) [15].

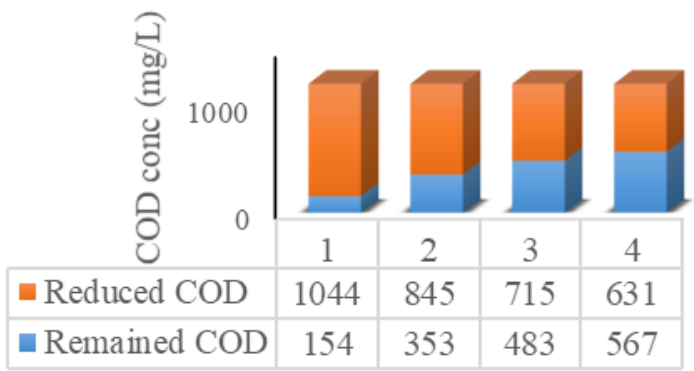

Fig. 2. The performance of reactor in $\mathrm{COD}$ reduction in presence of salt, $\mathrm{H}_{2} \mathrm{SO}_{4}, \mathrm{Fe}_{2} \mathrm{SO}_{4}$ (1); salt, $\mathrm{H}_{2} \mathrm{SO}_{4}$ (2); $\mathrm{H}_{2} \mathrm{SO}_{4}$ (3) and salt (4)

However, this mechanism contributes less to the process even in the presence of noble metal $(\mathrm{Pt})$ with its high electroactivity. It was due to the formation of polymer on anode surface leading into a reduction of adsorption and oxidation rate [15]. Whereas indirect oxidation has a higher contribution in which the material of anode will generate oxidator on certain applied potential. The type of oxidator generated greatly depends on the electrolyte used. Reactions of oxidation are defined as follows [16]:

$$
\mathrm{Ti} / \mathrm{PtIr}+\mathrm{H}_{2} \mathrm{O} \rightarrow \text { Ti/PtIr( }\left({ }^{\circ} \mathrm{OH}\right)+\mathrm{H}^{+}+\mathrm{e}^{-}
$$

$$
\mathrm{Ti} / \operatorname{PtIr}(\cdot \mathrm{OH})+\underset{\text { product }}{\text { pollutant }} \rightarrow \mathrm{Ti} / \mathrm{PtIr}+\text { oxidation }
$$

The material of cathode plays an important role in the mechanism of EFRP oxidation. Electrode will donate its electron to hydrogen and oxygen, and peroxide acid will be formed. It will then react with Ferro $\left(\mathrm{Fe}^{2+}\right)$ to form oxidator as the main subject of pollutant degradation in the liquid phase as given in reactions $3-5[17,18]$ :

$$
\begin{gathered}
2 \mathrm{H}^{+}+\mathrm{O}_{2}+2 \mathrm{e}^{-} \rightarrow \mathrm{H}_{2} \mathrm{O}_{2} \\
\mathrm{H}_{2} \mathrm{O}_{2}+\mathrm{Fe}^{2+} \rightarrow \mathrm{Fe}^{3+}+\mathrm{HO}^{-}+{ }^{\circ} \mathrm{OH}
\end{gathered}
$$




$$
\cdot \mathrm{OH}+\text { pollutant } \rightarrow \text { oxidation product }
$$

The mechanism of COD reduction via EFP was contributed by both anode and cathode. Both materials will produce hydrogen and oxygen as described in reactions (6-7) [17,19,20]:

$$
\begin{aligned}
& \text { Anode: } \mathrm{H}_{2} \mathrm{O} \rightarrow 1 / 2 \mathrm{O}_{2}+2 \mathrm{H}^{+}+2 \mathrm{e} \\
& \text { Cathode: } 2 \mathrm{H}_{2} \mathrm{O}+2 \mathrm{e} \rightarrow \mathrm{H}_{2}+2 \mathrm{OH}^{-}
\end{aligned}
$$

Both gases are released as fine bubbles that will effectively float insoluble solid pollutants to the water surface. Interaction between insoluble solids and the bubbles is basically based on the distinctive properties of hydrophobic and hydrophilic groups. This phenomenon was evident by the formation of fine sludge on water surface floated by bubbles generated by anode and cathode.

COD removal was highly influenced by chemicals used. COD removal was reduced when we only used 2 or 1 chemicals and achieved $70 \%, 60 \%$, and $53 \%$ by using salt and sulphuric acid, sulphuric acid only, and salt only, respectively. It was possible due to the reduced production of $\mathrm{OH}$ radicals generated by EFRP mechanism. Mousset et al, 2019 [21] reported that the oxidation pathway of electrochemical Fenton was highly effective for pollutant degradation due to its presence in the liquid phase. The role is dominant in low COD concentration. In contrast, EAOP will be the dominant pathway in high COD. High residual COD $(567 \mathrm{mg} / \mathrm{L})$ at the salt-only experiment was possibly due to the degradation mechanism dominated by EAOP instead of EFP and EFRP. COD removal by EAOP pathway was effective only at high COD concentration [21].

\subsection{COD removal efficiency as an indicator of pollutants degradation}

COD removal efficiency of HAOP is depicted in Fig. 3. Pollutant reduction was continuously increased with longer operational time and reduction of $94 \%$ was reached after $9 \mathrm{~h}$. COD was dominantly decreased at an initial time of operation $(3 \mathrm{~h})$ due to the occurrence of all three oxidation pathways (EAOP, EFRP, and EFP) at high efficiency. However, in the next period of operation (more than $6 \mathrm{~h}$ ) COD removal was slowly reduced. The possible reason is that the decreasing performance contributed by EAOP and EFP. EAOP pathway only occurs on the surface of anode, which is highly influenced by diffusion and migration of pollutants. At high concentration, kinetic rate of pollutants to the surface of anode will increase the diffusion [21]. In addition, COD removal via EFP will not be effective after $3 \mathrm{~h}$, due to flotation of solid pollutants to water surface thus hydrogen and oxygen will be dominantly released to the air.

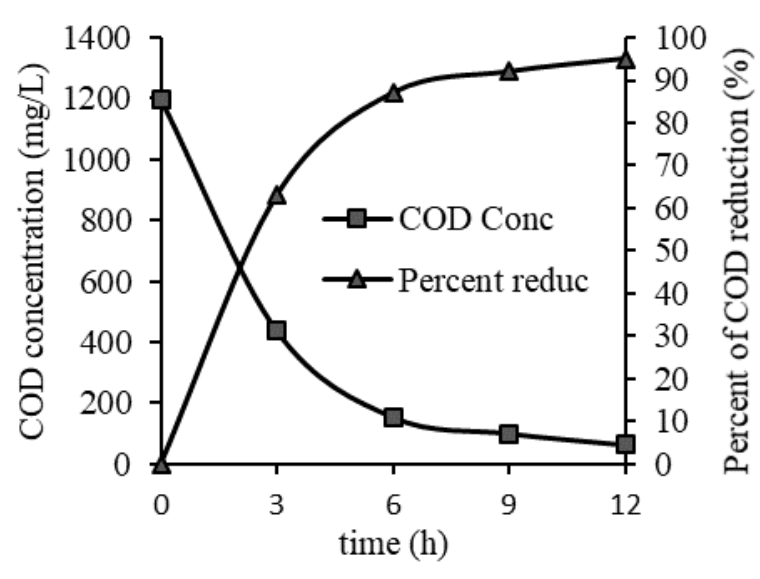

Fig. 3. Pollutant reduction during operational time

Figure 3 shows that after 6 hours HAOP has been able to fulfill the wastewater quality below the regional regulation. The performance of this technology is far superior to biology (DWA, SBR, UASB) and AOP (UVA-TiO2-photocatalysis) with COD removal of $83 \%$ [10] and $60 \%$ [22], respectively. High performance of COD removal and simple operational condition makes the HAOP highly potential as pharmaceutical wastewater treatment.

\subsection{Instantaneous current efficiency (ICE)}

Pollutant degradation contained in pharmaceutical wastewater occurred based on electrical energy, which is represented by potential and current. The efficiency value was calculated by correlation between current towards COD removal, as described in equation (19):

$I C E=\frac{\left[(C O D)_{t}-(C O D)_{t+\Delta t}\right]}{8 I \Delta t} x F x V_{s}$

Based on current and COD measurement, ICE value obtained is described in Table 1.

Table 1. Instantaneous current efficiency (ICE) obtained for pharmaceutical wastewater treatment

\begin{tabular}{|ccccc|}
\hline No & $\begin{array}{c}\mathbf{C O D}_{\mathbf{t}^{-}} \\
\mathbf{C O D}_{\mathbf{t}+\mathbf{t}} \\
(\mathbf{m g} / \mathbf{L})\end{array}$ & $\mathbf{I}(\mathbf{A})$ & $\mathbf{t} \mathbf{( h )}$ & $\begin{array}{c}\text { ICE } \\
\mathbf{( 1 0}^{-3} \mathbf{3}\end{array}$ \\
\hline 1 & 761 & 0,5275 & 3 & 0,4 \\
\hline 2 & 1044 & 0,4 & 6 & 0,35 \\
\hline 3 & 1098 & 0,42 & 9 & 0,24 \\
\hline 4 & 1135 & 0,42 & 12 & 0,18 \\
\hline
\end{tabular}

ICE value in Table 1 was calculated assuming that the main component of wastewater treated was antibiotic produced with a molecular weight of $800 \mathrm{~g} / \mathrm{mole}$. Low efficiency $\left(10^{-3}\right)$ showed that the antibiotic compound has a complex aromatic structure with a high difficulty of breakdown. ICE value was clearly decreasing over time, which was due to the dominant mechanism of EFP as a side reaction when all of the colloid phases has been floated. Moreover, EAOP pathway was reduced since 
the oxidation was limited by the diffusion of pollutant at low concentration.

\section{Conclusion}

HAOP technology shows a high performance of pharmaceutical wastewater treatment at 9 hours of operation. Salt, sulphuric acid and ferrous sulfate were main chemicals required to maintain performance of cell. COD was removed via three mechanisms, i.e., EAOP (electrochemical advanced oxidation process), EFRP (electrochemical Fenton reagent process) and EFP (electrochemical flotation process). Ti/PtIr anode and carbon cloth cathode were highly effective in supporting EAOP and EFRP pathways. EFP mechanism was dominant in pollutant degradation at initial operation and showed a decreased performance at a later period, which then affected the current efficiency (ICE).

This research has been supported by Center of Industrial Pollution Prevention Technology and Phapros Company in Semarang, Indonesia.

\section{References}

1. O. Lefebvre, X. Shi, C.H. Wu, H.Y. Ng, Biological treatment of pharmaceutical wastewater from the antibiotics industry, Water Sci. Technol. 69: 855861 (2014)

2. Z. Meng, Z. Juan, Wastewater treatment by photocatalytic oxidation of Nano- $\mathrm{ZnO} 2$ principles of photocatalytic oxidation ( Cui ( 2001 ), Lei ( 2001 )) Synthesization of Nano-ZnO, 12: 1-9 (2008)

3. M. Gros, M. Petrović, A. Ginebreda, D. Barceló, Removal of pharmaceuticals during wastewater treatment and environmental risk assessment using hazard indexes, Environ. Int. 36: 15-26 (2010)

4. W. Guo, R. Yin, X. Zhou, H. Road, Current Trends for Biological Antibiotic Pharmaceutical Wastewater Treatment, 2140-2145 (2013)

5. I. Michael, L. Rizzo, C.S. Mcardell, C.M. Manaia, C. Merlin, T. Schwartz, et al., Urban wastewater treatment plants as hotspots for the release of antibiotics in the environment: A review, Water Res. 47: 957-995 (2012)

6. W. Sim, J. Lee, J. Oh, Occurrence and fate of pharmaceuticals in wastewater treatment plants and rivers in Korea, Environ. Pollut. 158 (2010) 19381947. doi:10.1016/j.envpol.2009.10.036.

7. P. Zhou, M. Asce, C. Su, B. Li, Y. Qian, Treatment of High-Strength Pharmaceutical Wastewater and Removal of Antibiotics in Anaerobic and Aerobic Biological Treatment Processes, J Environ. Eng. ASCE. 132: 129-136 (2006)

8. H.F. HU Xiaodong, ZHANG Gang, SHI Yunfeng, Contrast experiment research an aerobic treatment of antibiotic wastewater, J. Guangzhou Univ. (Natural Sci. Ed. 33-36 (2010)

9. T. Coskun, H.A. Kabuk, K.B. Varinca, E. Debik, I. Durak, C. Kavurt, Bioresource Technology Antibiotic Fermentation Broth Treatment by a pilot upflow anaerobic sludge bed reactor and kinetic modeling, Bioresour. Technol. 121: 31-35 (2012)

10. M.S. Li Ning, Dai Qingwu, Wang Jun, Chen Yunxiang, Treatment of Antibiotic Production Wastewater by UASB, Environ. Prot. Chem. Ind. 30: 319-322 (2010)

11. Kurt, A., Mert, B.K., Özengin, N., Sivrioğlu, O and Yonar, T., Treatment of Antibiotics in Wastewater Using Advanced Oxidation Processes (AOPs), in: R. Farooq (Ed.), Physico-Chemical Wastewater Treat. Resour. Recover., IntechOpen (2017)

12. T. Yonar, Decolorisation of Textile Dyeing Effluents Using Advanced Oxidation Processes, in: P. Houser (Ed.), Adv. Treat. Text. Effl., IntechOpen, Europe 1-27 (2011)

13. A. Mukimin, H. Vistanty, N. Zen, A. Purwanto, K.A. Wicaksono, Performance of bioequalizationelectrocatalytic integrated method for pollutants removal of hand-drawn batik wastewater, J. Water Process Eng. 21: 77-83 (2018)

14. W. Buda, Photocatalytic treatment of pharmaceutical wastewater using new multiwallcarbon nanotubes / $\mathrm{TiO} 2$ / SiO 2 nanocomposites, 137: 176-184 (2015)

15. M. Panizza, G. Cerisola, Direct And Mediated Anodic Oxidation of Organic Pollutants, Chem. Rev. 109: 6541-6569 (2015)

16. C. Christos, Electrocatalysis In The Electrochemical Conversion / Combustion Of Organic Pollutants, Electrochem. Acta. 39: 18571862 (1994)

17. A.J. Bard, L.R. Faulkner, Electrochemical Methods: Fundamentals and Applications (2001)

18. L.G. Devi, S.G. Kumar, K.M. Reddy, C. Munikrishnappa, Photo degradation of Methyl Orange an azo dye by Advanced Fenton Process using zero valent metallic iron: Influence of various reaction parameters and its degradation mechanism, J. Hazard. Mater. 164: 459-467 (2009)

19. K. Rajeshwar, J.G. Ibanez, Environmental Electrochemistry: Fundamentals and Applications in Pollution Abatement, Academic Press, United Kingdom (1997)

20. M.M. Emamjomeh, M. Sivakumar, Review of pollutants removed by electrocoagulation and electrocoagulation/flotation processes, J. Environ. Manage. 90: 1663-1679 (2009)

21. E. Mousset, Y. Pechaud, N. Oturan, M.A. Oturan, Charge transfer/mass transport competition in advanced hybrid electrocatalytic wastewater treatment: Development of a new current efficiency relation, Applied Catal. B, Environ. 240: 102-111. (2019) 
22. S. Stets, J. Tamara, I. Ricardo, D. Barros, M. Vinícius, D. Liz, et al., Journal of Photochemistry and Photobiology A: Chemistry Antituberculosis drugs degradation by UV-based advanced oxidation processes, "Journal Photochem. Photobiol. A Chem. 353: 26-33 (2018) 